\title{
SEMINOMA E TUMOR DE CÉLULAS INTERSTICIAIS NO MESMO TESTÍCULO DE UM CÃO - RELATO DE CASO
}

\section{Érica Almeida Viscone ${ }^{1}$, Alessandra Castro Rodrigues ${ }^{1}$, Mariana Ribeiro de Castro1, Samyla de Almeida Silva', Lígia Fernandes Gundim²}

1- Residente em Patologia Animal, Universidade Federal de Uberlândia, Uberlândia - MG. E-mail: ericaviscone@gmail.com

2- Mestranda no Programa de Ciências Veterinárias da Universidade Federal de Uberlândia, Uberlândia - MG.

Recebido em: 03/10/2016 - Aprovado em: 21/11/2016 - Publicado em: 05/12/2016 DOI: 10.18677/EnciBio_2016B_087

\begin{abstract}
RESUMO
As neoplasias testiculares mais comuns em cães são o seminoma, o tumor de células intersticiais (tumor de células de Leydig) e o tumor de células de Sertoli. O tumor mais frequente é o tumor de células de Leydig, seguido pelo seminoma e sertolioma, podendo ocorrer isoladamente ou, menos frequentemente, juntos. Esse trabalho teve como objetivo relatar caso de um cão diagnosticado com seminoma e tumor de células intersticiais no setor de Patologia Animal da Universidade Federal de Uberlândia. O testículo esquerdo apresentava-se aumentado de volume e o direito sem alterações macroscópicas. A microscopia de luz, observou-se células neoplásicas arranjadas em manto e cordões, com citoplasma amplo e eosinofílico, núcleo com cromatina frouxa e nucléolo evidente, caracterizando tumor das células de Leydig. Na mesma amostra, ainda foram observadas células neoplásicas, arranjadas em manto, de localização intra e extratubulares, de formato arredondado, bordas definidas, citoplasma anfofílico, núcleo arredondado, excêntrico, cromatina frouxa e nucléolo evidente. Tais achados são característicos de seminona difuso. Este mesmo tipo tumoral também foi identificado no testículo direito.
\end{abstract}

PALAVRAS-CHAVE: canino, neopasia, testicular.

\section{SEMINOMA AND INTERSTITIAL CELLS TUMOR IN A DOG'S SAME TESTIS - CASE REPORT}

\begin{abstract}
Seminomas, Leydig cell tumors and Sertoli cell tumors represent the frequent types of canine testicular neoplasms. The most frequent type is Leydig cell tumors, followed by seminoma and Sertoli cell tumors, tumors can occurs in one or both testis at same time. The aim was report a dog diagnosed with seminoma and Leydig cells tumor, at Animal Pathology Department, Federal University of Uberlândia. The left testicle presented enlarged and the right without macroscopic changes. In light microscopy, there were neoplastic cells arranged in sheets and cords, with large, eosinophilic cytoplasm, nucleus with loose chromatin and evident nucleolus, characterizing tumor Leydig cells. In the same sample, we also observed neoplastic cells arranged in sheets, intra- and extratubulares location of rounded shape, sharp edges, amphophilic cytoplasm, nucleus rounded, eccentric, loose chromatin and
\end{abstract}


evident nucleolus. These findings are characteristic of diffuse seminona. The same kind of tumor was found at right testis.

KEYWORDS: neoplasm, canine, testicular.

\section{INTRODUÇÃO}

As neoplasias testiculares mais comuns em cães são o seminoma, o tumor de células intersticiais (tumor das células de Leydig) e o tumor de células de Sertoli (Sertolioma) e, dentre estes, o tumor das células de Leydig é o mais frequente. Em geral, são tumores benignos e raramente causam metástase, podendo ocorrer isoladamente ou juntos (FOSTER, 2013). Tumores testiculares acometem mais frequentemente cães senis e criptorquidas (DAVIDSON, 2015), sendo infrequentes em equinos e raros nas demais espécies (FOSTER, 2013).

Muitas vezes o diagnóstico do tumor no testículo é um achado acidental por meio da palpação, durante a avaliação clínica (DAVIDSON, 2015). Enquanto no sertolioma, o testículo apresenta-se de consistência firme a dura à palpação e de coloração brancacenta, no seminoma observam-se apenas aumento de volume e coloração cinza-esbranquiçada ao corte, já no tumor de células intersticiais é possível distinguir a área do nódulo e este apresenta cor amarelada, podendo ter áreas hemorrágicas ou císticas (MACLACHLAN \& KENNEDY, 2002). A ultrassonografia pode ser usada como exame auxiliar na detecção do tumor, na qual nota-se mudança de padrão hiperecoico para ecogenicidade mista, demonstrando apenas o crescimento, não sendo específico para cada tipo de tumor (DAVIDSON, 2015).

O diagnóstico definitivo é dado através da histopatologia. No sertolioma, notase acúmulo de células de Sertoli separadas por estroma fibroso abundante. No seminoma, observam-se túbulos ou ninhos de células poliédricas com núcleo grande e vesicular e citoplasma escasso e basofílico, enquanto no tumor de células intersticiais pode-se visualizar células poliédricas, porém com núcleo pequeno e escuro com citoplasma abundante, podendo conter gotículas de lipídeos (MACLACHLAN \& KENNEDY, 2002).

Como tratamento, recomenda-se a orquiectomia, podendo ser unilateral caso o animal esteja em reprodução e a neoplasia acometa apenas um dos testículos (DAVIDSON, 2015). Objetivou-se relatar o caso de um cão diagnosticado com seminoma e tumor de células intersticiais localizados no mesmo testículo.

\section{RELATO DE CASO}

Um cão, sem raça definida, treze anos, apresentou aumento progressivo do testículo esquerdo no período de 30 dias, sendo esta a única alteração observada pelo tutor. Como exame complementar, realizou-se ultrassonografia de bolsa escrotal, observou-se testículo esquerdo com parênquima hiperecoico e uma estrutura de contorno regular, heterogênea e hiperecoica, projetando-se do parênquima. Testículo direito com arquitetura aparentemente normal.

A avaliação clínica indicou neoplasia testicular e o animal foi encaminhado ao setor de Cirurgia de Animais de Companhia, do Hospital Veterinário da Universidade Federal de Uberlândia, para orquiectomia bilateral. Fragmentos dos testículos direito e esquerdo foram encaminhados ao setor de Patologia Animal, da mesma instituição, para exame histopatológico. No mínimo três secções de cada testículo foram fixadas em formol $10 \%$ tamponado, desidratadas em álcoois, embebidas em 
blocos de parafina, seccionadas em série e as lâminas montadas e coradas rotineiramente com hematoxilina e eosina.

\section{RESULTADOS E DISCUSSÃO}

Ao exame macroscópico, o testículo esquerdo estava aumentado de volume, consistência firme, superfície lisa e com pouca mobilidade em escroto. O testículo direito apresentava características macroscópicas normais.

$\mathrm{Na}$ avaliação histopatológica do testículo esquerdo, à microscopia de luz, observou-se células neoplásicas arranjadas em manto e cordões, separadas por fino estroma de tecido conjuntivo, com citoplasma amplo e eosinofílico, núcleo com cromatina frouxa e nucléolo evidente (Figura 1), caracterizando tumor das células de Leydig. CANADAS et al. (2016) descreveram tumor das células de Leydig em um cão, 11 anos de idade e BANCO et al. (2016) em cinco cães com idade variando de 9 a 13 anos.

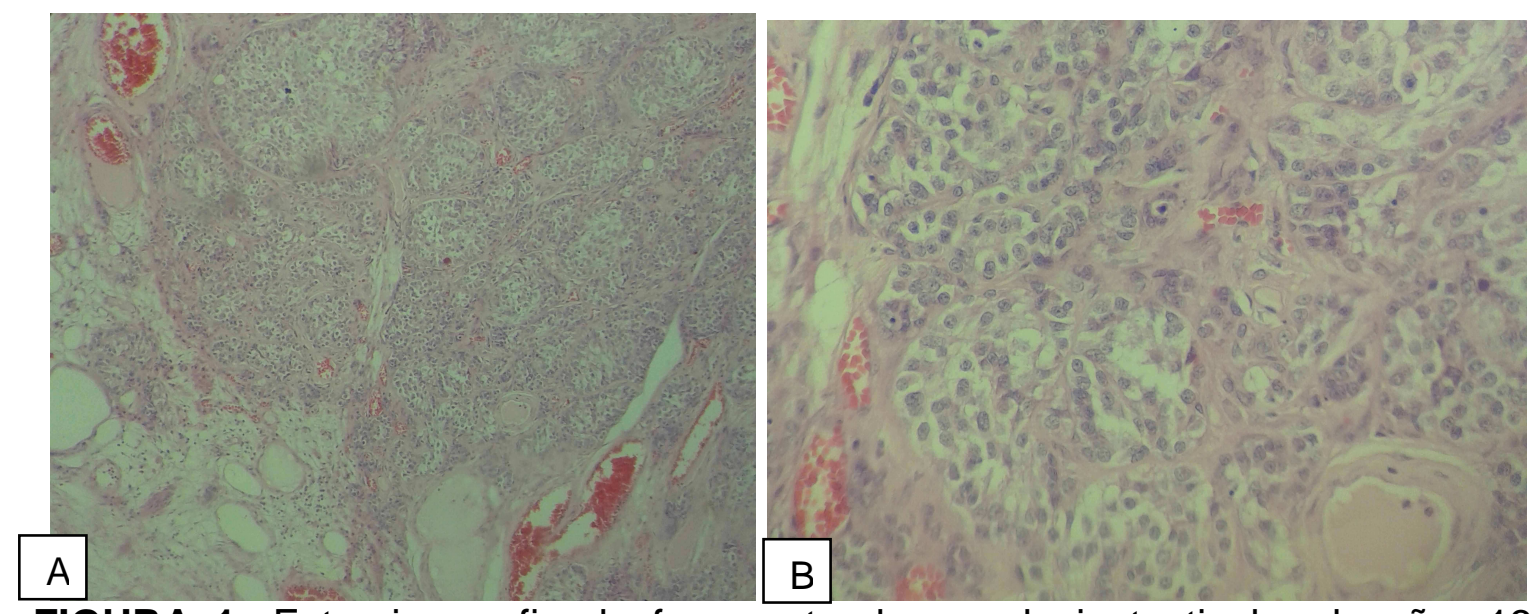

FIGURA 1: Fotomicrografia de fragmento de neoplasia testicular de cão, 13 anos. (A) notar células neoplásicas arranjadas em manto e cordões. Objetiva 10x. HE. (B) células neoplásicas com citoplasma amplo e eosinofílico, núcleo com cromatina frouxa e nucléolo evidente. Objetiva 40x.HE. Fonte: arquivo pessoal.

$\mathrm{Na}$ mesma amostra do testículo esquerdo, ainda foram observadas células neoplásicas, arranjadas em manto, de localização intra e extratubulares, de formato arredondado, bordas definidas, citoplasma anfofílico, núcleo arredondado, excêntrico, cromatina frouxa e nucléolo evidente (Figura 2). Tais achados são característicos de seminoma difuso e também foram relatados por CIAPUTA et al, (2012) em um cão da raça Labrador Retriever, 10 anos e MACLACHLAN \& KENNEDY (2002). 


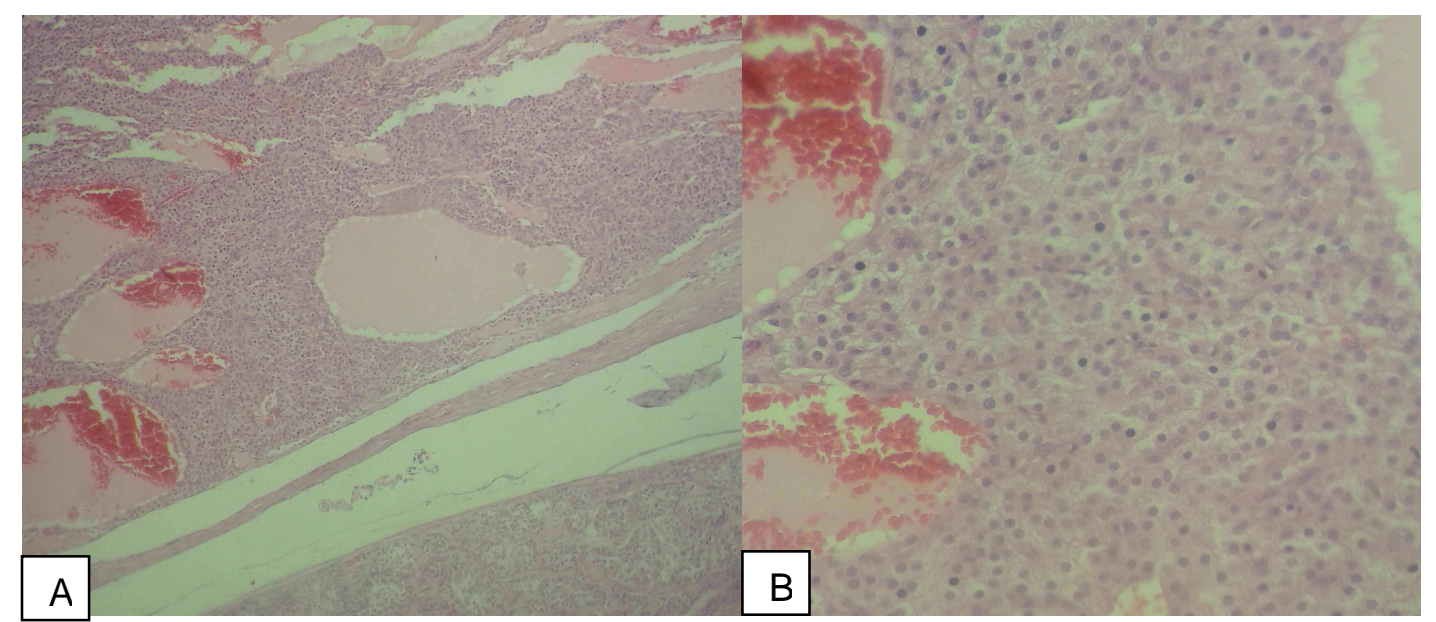

FIGURA 2: Fotomicrografia de fragmento de neoplasia testicular de cão, 13 anos. (A) notar células neoplásicas, arranjadas em manto, intra e extratubulares. HE. Aumento 10x. (B) células neoplásicas de formato arredondado, bordas definidas, citoplasma anfofílico, núcleo arredondado, excêntrico, cromatina frouxa e nucléolo evidente. HE. Aumento 40x. Fonte: arquivo pessoal.

Apesar de, macroscopicamente, o testículo direito não apresentar alterações, na avaliação histopatológica observou-se células neoplásicas, arranjadas em manto, de localização intra e extratubulares, formato arredondado, bordas definidas, citoplasma anfofílico, núcleo arredondado, excêntrico, cromatina frouxa e nucléolo evidente (Figura 3). Da mesma forma, compatíveis com seminoma difuso, seguindo os achados de CIAPUTA et al., (2012) e MACLACHLAN \& KENNEDY (2002).

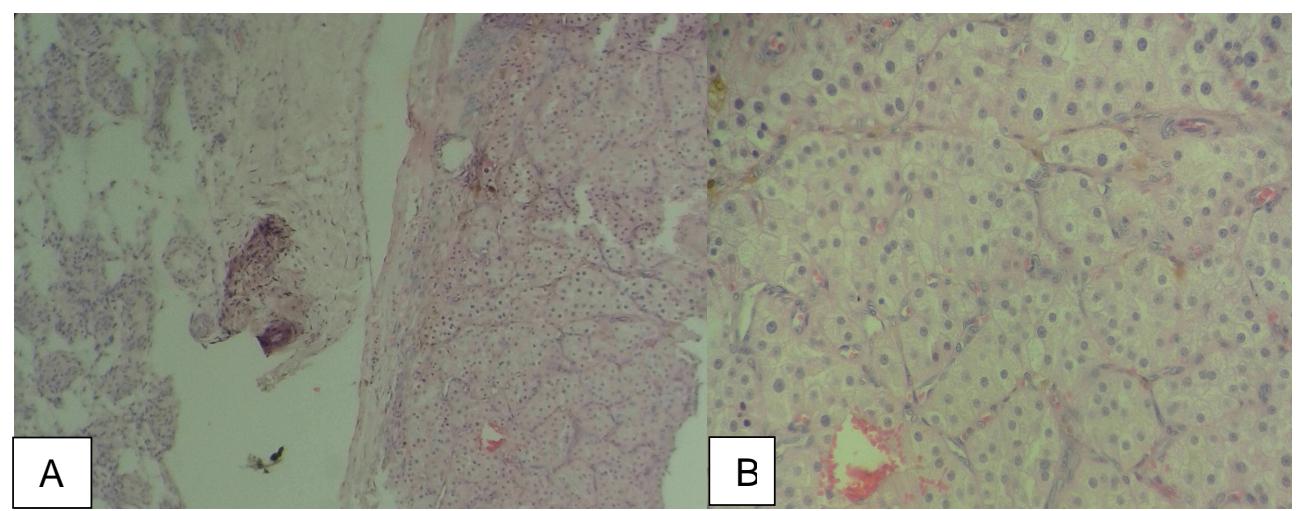

FIGURA 3: Fotomicrografia de fragmento de neoplasia testicular de cão. Seminoma. (A) células neoplásicas, arranjadas em manto, intra e extratubulares. HE. Aumento 10x. (B) células neoplásicas de formato arredondado, bordas definidas, citoplasma anfofílico, núcleo arredondado, excêntrico, cromatina frouxa e nucléolo evidente. HE. Aumento 40x. Fonte: arquivo pessoal.

Segundo FOSTER (2013), Leydig \& seminoma são tumores frequentes e podem ocorrer isoladamente ou, menos frequente, juntos, assim como no presente estudo. SOZMEN et al. (2013) encontraram a combinação de dois tipos de tumores ENCICLOPÉDIA BIOSFERA, Centro Científico Conhecer - Goiânia, v.13 n.24; p.921 2016 
em cinco cães, sendo: dois cães com tumor de células intersticiais (Leydig) e tumor de células de Sertolli; dois cães com tumor de células intersticiais e seminoma; um cão com seminoma e tumor de células de Sertolli, concluindo que os cães podem ter mais de um tipo de tumor em um ou ambos os testículos. Ainda, 18 dos 47 cães estudados (38,29\%) por SANTOS et al. (2000) apresentaram mais de um tipo de tumor testicular, com a combinação de seminoma e tumor de células intersticiais se mostrando mais frequente, 10 casos, seguido pela combinação de tumor de células intersticiais e tumor das células de Sertoli com quatro casos, seminoma e tumor das células de Sertoli com dois casos e seminoma e tumor das células de Leydig com dois casos.

\section{CONCLUSÃO}

A ocorrência de tumores testiculares diferentes em um mesmo animal, apesar de pouco frequente, deve ser investigada, no caso de aumento de volume testicular ou não, uma vez que testículos sem alterações macroscópicas também podem apresentar o tumor. A avaliação histopatológica é útil na determinação do tipo tumoral.

\section{REFERÊNCIAS}

BANCO, B.; PALMIERI, C.; SIRONI, G.; FANTINATO, E.; VERONESI, M. C.; GROPPETTI, D.; GIUDICE, C.; MARTIGNONI, B.; GRIECO, V. Immunohistochemical expression of SOX9 protein in immature, mature, and neoplastic canine Sertoli cells. Theriogenology, v. 85, n. 8, p. 1408-1414. e1, 2016. Disponível em:

http: http://www.sciencedirect.com/science/article/pii/S0093691X15006998 Doi: 10.1016/j.theriogenology.2015.12.024

CANADAS, A.; ROMÃO, P.; GÄRTNER, F. Multiple Cutaneous Metastasis of a Malignant Leydig Cell Tumour in a Dog. Journal of Comparative Pathology, v. 155, n. 2 2, p. 181-184, 2016. Disponível em: http: http://www.sciencedirect.com/science/article/pii/S0021997516300512 Doi: 10.1016/j.jcpa.2016.05.012

CIAPUTA, Rafał et al. Seminoma, sertolioma, and leydigoma in dogs: clinical and morphological correlations. Bulletin of the Veterinary Institute in Pulawy, v. 56, n. 3, p. 361-367, 2012. Disponível em: http: https://www.researchgate.net/publication/269513579_Seminoma_Sertolioma_and_L eydigoma_in_Dogs_Clinical_and_Morphological_Correlations

DAVIDSON, A.T. Distúrbios do Sistema Reprodutor. IN: NELSON, Richard; COUTO, C. Guillermo. Medicina interna de pequenos animais. 5.ed. Rio de Janeiro: Elsevier Brasil, 2015, p 949.

FOSTER, R. A. Sistema Reprodutivo do Macho. In McGAVIN, M.D; ZACHARY, J. F. Bases da Patologia em Veterinária. 5 ed. Rio de Janeiro: Elsevier, 2013. p 1317 $-1348$. 
MACLACHLAN N.J.; KENNEDY P.C. Tumors of the genital system. In.D.J. Meuten (Ed.), Tumors in Domestic Animals (4th edit.), lowa State Press, Ames (2002), pp. $547-573$.

SANTOS, R.L.; SILVA, C.M.; RIBEIRO, A.F.C.; SERAKIDES, R. Testicular tumors in dogs: frequency and age distribution. Arq. Bras. Med. Vet. Zootec., Belo Horizonte , v. 52, n. 1, p. 25-26, Feb. 2000. Disponível em: http: http://www.scielo.br/scielo.php?script=sci_arttext\&pid=S0102-09352000000100007 Doi: /10.1590/S0102-09352000000100007

SOZMEN, M., KABAK, Y. B., GULBAHAR, M. Y., GACAR, A., KARAYIGIT, M. O., GUVENC, T., \& YARIM, M. (2013). Immunohistochemical characterization of peroxisome proliferator-activated receptors in canine normal testis and testicular tumours. Journal of comparative pathology, 149(10 -18). Disponível em: http: http://www.sciencedirect.com/science/article/pii/S0021997512001661

Doi:

10.1016/j.jcpa.2012.09.010 